\title{
Tumor Necrosis Factor in Mediating Experimental Haemophilus influenzae Type B Meningitis
}

\author{
Mahmoud M. Mustafa, Octavio Ramilo, Kurt D. Olsen, Patricia S. Franklin, \\ Eric J. Hansen, Bruce Beutler, and George H. McCracken, Jr. \\ Departments of Pediatrics and Microbiology, Academic Computing Services and Howard Hughes Medical Institute, \\ The University of Texas Southwestern Medical Center, Dallas, Texas 75235
}

\begin{abstract}
Tumor necrosis factor (TNF) could possibly be instrumental in mediating injury to the CNS during bacterial meningitis. In CSF of rabbits with meningitis induced with Haemophilus influenzae type b (Hib) lipooligosaccharide (LOS), TNF activity was first detected 45 min after intracisternal (IC) injection of 20 ng Hib LOS and white blood cells (WBC) first appeared 75 min later. The peak TNF activity $(45 \mathrm{ng} / \mathrm{ml}$ ) was observed at $120 \mathrm{~min}$ after IC and persisted for $5 \mathrm{~h}$. When 1-2 $\times 10^{7} \mathrm{CFU}$ of Hib was used to induce meningitis, peak CSF TNF activity was comparable with that after 20 ng Hib LOS, but the activity persisted for $14 \mathrm{~h}$.

Dexamethasone (DXM) (1 mg/kg per i.v.) given $1 \mathrm{~h}$ before or simultaneously with IC Hib LOS reduced significantly TNF activity and meningeal inflammation. Goat anti-human TNF $\alpha$ antibodies given IC with $20 \mathrm{ng}$ Hib LOS or $2 \times 10^{6} \mathrm{CFU}$ of Hib resulted in a significant reduction in CSF TNF concentrations, which was also associated with reduced meningeal inflammation in Hib LOS-inoculated animals. We conclude that TNF participates in mediating meningeal inflammation associated with Hib experimental meningitis, and that DXM, when given before or with Hib LOS, inhibits CSF TNF production and modulates the meningeal inflammatory response.
\end{abstract}

\section{Introduction}

Tumor necrosis factor alpha (TNF, cachectin) ${ }^{1}$ is a macrophage polypeptide hormone secreted in response to microbial or endotoxin stimulation. Prominent among its biological effects is the ability to induce wasting as well as a lethal state of shock (1). It was recently shown that endotoxin elicits the production of several peptide cytokines (TNF $\alpha$, interleukin-1, interferons) which in turn lead to shock and death (2-6). TNF appears to fulfill a central role in fatal endotoxemia (7).

TNF was first considered as a mediator of endotoxin-induced tissue injury and shock after Beutler et al. (8) purified

Address reprint requests to Dr. McCracken, Department of Pediatrics, University of Texas Southwestern Medical Center, Dallas, 5323 Harry Hines Boulevard, Dallas, TX 75235.

Received for publication 12 September 1988 and in revised form 15 June 1989.

1. Abbreviations used in this paper: DXM, dexamethasone; Hib, Haemophilus influenzae type b; IC, intracisternal injection; LOS, lipooligosaccharide; TNF, tumor necrosis factor.

J. Clin. Invest.

(c) The American Society for Clinical Investigation, Inc. $0021-9738 / 89 / 10 / 1253 / 07 \$ 2.00$

Volume 84, October 1989, 1253-1259 this cytokine and demonstrated that TNF played a major role in the severe metabolic effects of endotoxin-mediated shock $(5,9)$. Confirmatory studies showed later that pretreatment of baboons with a monoclonal antibody to TNF prevented death after intravenous injection with a lethal dose of live Escherichia coli organisms (10). Additionally, experimental studies in human volunteers $(11,12)$ and animals (10-13) given live bacteria or endotoxin intravenously have quantified and correlated TNF serum concentrations with pathophysiological changes, and with the host's inflammatory response.

In contrast to the rapid rate with which new information on TNF as a mediator of experimental endotoxic shock and of gram-negative septicemia (13-15) has accumulated, the role of TNF in the pathogenesis of bacterial meningitis has not been well studied. TNF has been detected in CSF of infants and children with bacterial meningitis $(16,17)$ and in pooled CSF of mice during meningitis induced with Listeria organisms inoculated intracerebrally (17). Consequently, we examined the time course and dose-dependent response of TNF in the CSF of rabbits after induction of meningitis with either Haemophilus influenzae type $\mathrm{b}(\mathrm{Hib})$ or a highly purified preparation of Hib lipooligosaccharide (LOS). In addition, we evaluated the effects of dexamethasone given intravenously or of anti-human TNF $\alpha$ goat serum given intracisternally on CSF TNF concentrations and on the subsequent meningeal inflammatory response.

\section{Methods}

Bacterial strain. Hib strain DL42 is a non-beta-lactamase producing strain isolated from the CSF of a child with meningitis. This strain is virulent in the infant rat model for Hib invasive disease and belongs to LOS antigenic group 2, which is the predominant LOS antigenic type among invasive Hib strains (18).

Preparation of Hib DL42 LOS. LOS was purified from cells of Hib strain DL42 by using the hot phenol-water method of Westphal and Jann (19) as modified by Johnson and Perry (20). The purity of this LOS preparation was confirmed by sodium dodecyl sulfate (SDS)polyacrylamide gradient gel electrophoresis (PAGE) followed by silver staining (21) and Western blot analysis using hyperimmune rat serum to Hib DL42 (22).

It has been shown previously that Hib LOS, in either its purified form or as an integral part of the outer membrane of Hib, when injected intracisternally induces meningeal inflammation and alteration of blood-brain barrier permeability (23-25). The minimal amounts of LOS necessary to produce CSF pleocytosis and elevation in CSF protein concentrations were 0.02 and $2 \mathrm{ng}$, respectively. Intracisternal injection of $20 \mathrm{ng}$ of Hib LOS consistently induced substantial changes in the indices of meningeal inflammation (23); this amount of LOS is contained in $\sim 2 \times 10^{6} \mathrm{Hib}$ cells. Because CSF samples from patients with $\mathrm{Hib}$ meningitis contain from $10^{4}$ to $10^{7} \mathrm{CFU} / \mathrm{ml}, 20 \mathrm{ng}$ of Hib LOS was chosen as an appropriate inoculum to induce meningitis in our studies. By contrast, the use of live organisms to induce menin- 
gitis was associated with inconsistent results principally as a result of an inconstant number of Hib in CSF at various intervals after inoculation.

Polyclonal anti-TNF antibody. Polyclonal anti-human TNF antibody was produced by immunizing goats with human recombinant TNF. Both anti-human TNF serum and preimmune goat serum were kindly provided by Drs. John C. Mathison and Richard J. Ulevitch, Department of Immunology, Research Institute of Scripps Clinic, La Jolla, CA. The method of production of the polyclonal anti-TNF antibody have been described elsewhere (13).

The preimmune and immune goat sera were tested previously for antibodies specific for Salmonella minnesota RE 595 LPS using an enzyme-linked immunoassay (13). Specific anti-Re 595 LPS antibodies were not detected indicating that immunization of the goats with TNF did not induce an anti-LPS response. Because Hib LOS and LPS share the same lipid A moiety, the active part of the molecule, antibodies against LOS lipid A are not expected to be present in the goat immune serum that has been used in our experiments. Antibodies that may be present in the goat-antiserum that can bind to epitopes in the oligosaccharide region of Hib LOS will not affect the potency of the LOS molecule in the rabbit meningitis model (23).

The neutralizing capacity of the antibody was determined and published previously (13). In vitro, an 80 - to 100 -fold dilution of antibody neutralized $50 \%$ of cytolytic activity of rabbit TNF $(10-20 \mathrm{ng} / \mathrm{ml})$ when equal volumes were mixed and incubated for $1 \mathrm{~h}$ at $37^{\circ} \mathrm{C}$. Additionally, 10-fold diluted goat anti-HrTNF neutralized more than $95 \%$ of cytolytic activity $(20-30 \mathrm{ng} / \mathrm{ml})$ of rabbit serum collected after injection of $10 \mu \mathrm{g}$ i.v. of Re 595 LPS (13).

When tested in a chromogenic Limulus assay, endotoxin contamination was observed to be $<0.5 \mathrm{ng} / \mathrm{ml}$ (13). More importantly, when $0.4 \mathrm{ml}$ of the immune serum was injected directly into the cisterna magna of rabbits it did not induce appreciable meningeal inflammation (maximum CSF pleocytosis of $250 \mathrm{wbc} / \mathrm{mm}^{3}$.

Cytolytic assay for tumor necrosis factor. TNF activity was determined by modification of a previously described cytotoxic assay (26). Briefly, L929 cells (CCL 1; American Type Culture Collection, Rockville, MD) were maintained in Dulbecco's modified eagle medium supplemented with $10 \%$ fetal bovine serum and $4 \%$ penicillin and streptomycin concentrate (Gibco Laboratories, Grand Island, NY). Confluent cultures were rinsed with sterile PBS, then exposed to $0.05 \%$ trypsin in Hanks' balanced salt solution, pelleted by centrifugation, resuspended in fresh medium, and added to 96 well plates $\left(7 \times 10^{4}\right.$ cells/well) in a volume of $100 \mu \mathrm{l} /$ well. After $2-3 \mathrm{~h}$ in culture, $50 \mu \mathrm{l}$ of cycloheximide $(0.3 \mathrm{mg} / \mathrm{ml})$ and $3 \mu \mathrm{l}$ of CSF samples were added to each well and the plates were incubated overnight $\left(5 \% \mathrm{CO}_{2}, 37^{\circ} \mathrm{C}\right)$. After microscopic evaluation, the medium was decanted, and the wells were filled with $100 \mu \mathrm{l}$ of $0.5 \%$ crystal violet in $25 \%$ methanol for 5 min, washed thoroughly with normal saline, and dried. The dye was solubilized with $100 \mu \mathrm{l}$ of $50 \%$ acetic acid. The degree of cytotoxicity was quantified spectrophotometrically $(490 \mathrm{~nm})$ using a computerized automated ELISA plate reader (model 2550 EIA Reader; Bio-Rad Laboratories, Hercules, CA). Equivalent concentrations of recombinant human TNF were determined for experimental samples by interpolation of the recombinant human TNF standard curve run simultaneously $(0.1 \mathrm{pg} / \mathrm{ml}-1 \mu \mathrm{g} / \mathrm{ml})$. Using this assay, we could reliably detect as little as $50 \mathrm{pg}$ of rabbit TNF per ml. The samples were assayed in quadruplicate, and a standard deviation within $10 \%$ of the mean was observed. The $\mathrm{L} 929$ cells are unaffected by IL-1. Representative CSF specimens containing TNF obtained from rabbits with meningitis induced with Hib or Hib LOS were preincubated with polyclonal antiTNF antibody which, when tested in parallel with the CSF samples before incubation, showed complete elimination of the cytotoxicity. TNF is stable for long periods when stored at $-70^{\circ} \mathrm{C}$.

To rule out the possibility that an inhibitor of cytolytic TNF activity was released by pretreatment with dexamethasone (DXM), the following in vitro study was performed. CSF samples from DXM pretreated and untreated rabbits were mixed in 1:1 and 2:1 ratios, incubated for $15 \mathrm{~min}$ and then tested for TNF cytolytic activity. Unmixed samples were also tested simultaneously. CSF TNF activity from
DXM-untreated rabbits was similar when CSF samples were tested alone or when mixed with CSF samples from steroid-treated animals, indicating that pretreatment with steroids did not induce formation of inhibitors of cytolytic TNF activity.

Measurement of CSF lactate, protein and glucose concentrations. CSF samples were analyzed for lactate with a kinetic enzymatic method that used the reaction of lactate with $\beta-\mathrm{NAD}^{+}$in the presence of lactate dehydrogenase to produce NADH and pyruvate. The production of NADH was quantitatively monitored at a $340 \mathrm{~nm}$ absorbance on a spectrophotometer (2600; Gilford, Oberlin, $\mathrm{OH}$ ) with a deuterium source. The precision of the method was tested by running a known standard of $40 \mathrm{mg} / \mathrm{dl}$ (UV test 826-UV; Sigma Chemical Co., St. Louis, MO) 10 times over the course of $1 \mathrm{~d}$. The coefficient of variation was $2.2 \%$.

Protein concentrations were determined using the turbidity method. The turbidity produced by sulfosalicylic acid when added to a solution containing protein, is proportional to the concentration of the protein in the solution. The turbidity was measured using a spectrophotometer set at $420 \mathrm{~nm}$. Sigma protein standard (P-7656) as a control was assayed with each run.

Glucose concentrations were determined using a commercially available colorimetric test Ektachem (Kodak, Rochester, NY).

Meningitis model and in vivo experiments. A model of experimental meningitis originally described by Dacey and Sande (27) was used in a modified form. New Zealand white male rabbits $(2-3 \mathrm{~kg})$ were anesthetized with intramuscular injections of ketamine $(40 \mathrm{mg} / \mathrm{kg})$ and acepromazine $(3 \mathrm{mg} / \mathrm{kg})$ and immobilized in a stereotactic frame. A spinal needle 3.5 in., 20 gauge) was introduced into the cisterna magna and $0.2 \mathrm{ml} \mathrm{CSF}$ withdrawn. The animals were then inoculated intracisternally (i.c.) with one of the following test materials:

1. 2, 20, and $200 \mathrm{ng}$ of purified Hib LOS (four, eight, four rabbits, respectively)

2. Hib $1-2 \times 10^{7} \mathrm{CFU}$ (four rabbits)

3. $20 \mathrm{ng}$ of purified Hib LOS alone or with dexamethasone (Merck Sharp \& Dohme, West Point, PA) $1 \mathrm{mg} / \mathrm{kg}$ i.v. administered at the following times in relation to the time of Hib LOS inoculations:

i. $1 \mathrm{~h}$ before (four rabbits)

ii. simultaneously (four rabbits)

iii. $30 \mathrm{~min}$ after (four rabbits)

iv. No dexamethasone (six rabbits)

4. $20 \mathrm{ng}$ of purified Hib LOS alone (six rabbits), with $0.4 \mathrm{ml}$ of polyclonal anti-TNF antibody (four rabbits) or with $0.4 \mathrm{ml}$ of preimmune goat serum (three rabbits)

5. Control animals (four rabbits) injected with $0.2 \mathrm{ml}$ of pyrogenfree saline

6. Hib $2 \times 10^{6} \mathrm{CFU}$ (six rabbits); with polyclonal anti-TNF antibody (three rabbits) or with preimmune goat serum (three rabbits). Two doses, $0.3 \mathrm{ml}$ each, of polyclonal anti-TNF antibody or preimmune goat serum were given at the time of and $1 \mathrm{~h}$ after Hib inoculation.

Every $30 \mathrm{~min}$ after IC inoculation for $4 \mathrm{~h}, 0.2 \mathrm{ml} \mathrm{CSF}$ samples were obtained and analyzed immediately for cell count using a Neuber hematocytometer (American Optical, Buffalo, NY). The specific time points were chosen according to our preliminary experiments, which showed that TNF persisted in the CSF of rabbits for 4-5 $\mathrm{h}$ after LOS inoculation. When Hib organisms were used the period of sampling was extended to $16 \mathrm{~h}$. Although $0.2 \mathrm{ml}$ of CSF every $30 \mathrm{~min}$ were withdrawn for $4 \mathrm{~h}$ (a total of $1.6 \mathrm{ml}$ ), the effect of sampling on later values during the experiment is believed to be minimal because the total volume of CSF in a 2-3-kg rabbit is 4-5 ml. It is possible to withdraw at one time as much as $1.6-1.7 \mathrm{ml}$ of CSF from the cisterna of these animals, but this was not done in any of our experiments. Immediately after collection, CSF aliquots were centrifuged $(5,000$ $\mathrm{rpm}, 5 \mathrm{~min}$ ) and the supernatant was stored at $-70^{\circ} \mathrm{C}$ until assayed for TNF, protein, glucose, and lactate concentrations. When Hib was used to induce meningitis, sampling continued hourly for $16 \mathrm{~h}$. 
Statistical methods. Two-way repeated measures analysis of variance was used to assess the effect of independent treatments with time for the following variables: WBC, lactate, protein, glucose, and TNF. If the group by time interaction was significant at the 0.10 level, then pairwise comparisons were made for groups at each specific time and within a group for different time periods. A Bonferroni approach (28) was utilized for the pairwise comparisons with the 0.05 level considered significant.

In the LOS dose-dependent study, the groups were doses at 2, 20, and $200 \mathrm{ng}$ and the times were $60,90,120$, and $180 \mathrm{~min}$. In the dexamethasone study the groups were defined according to the administration of dexamethasone ( $-1 \mathrm{~h}, 0$ time and $+30 \mathrm{~min}$ and a control) and times ranged from 60 to $240 \mathrm{~min}$ in 30 -min increments.

In the antiserum study, independent groups were antiserum, preimmune serum, and control at seven different times from 0 to $6 \mathrm{~h}$. LOS effect on TNF was compared to Hib at four different times: 1, 2, 3 , and $4 \mathrm{~h}$.

The relations of TNF concentrations to protein, WBC, lactate, and glucose concentrations $1 \mathrm{~h}$ later were assessed with the calculation of Pearson correlation coefficients combining values for TNF at 1,2 , and $3 \mathrm{~h}$ with appropriate protein, WBC, lactate, and glucose data.

Data are given as means \pm standard errors unless otherwise indicated.

\section{Results}

CSF concentrations of TNF. TNF activity in CSF of healthy, uninfected rabbits was below the limits of detection of the bioassay. TNF activity was first observed at $45 \mathrm{~min}$ after induction of meningitis by Hib LOS and persisted for $4 \mathrm{~h}$ (Fig. 1 $A$ ). A mean peak TNF concentration of $43.3 \pm 2.2 \mathrm{ng} / \mathrm{ml}$ was noted at $2 \mathrm{~h}$ after endotoxin challenge and this value was significantly larger than that detected $1 \mathrm{~h}$ after IC LOS $(23 \pm 3.1$
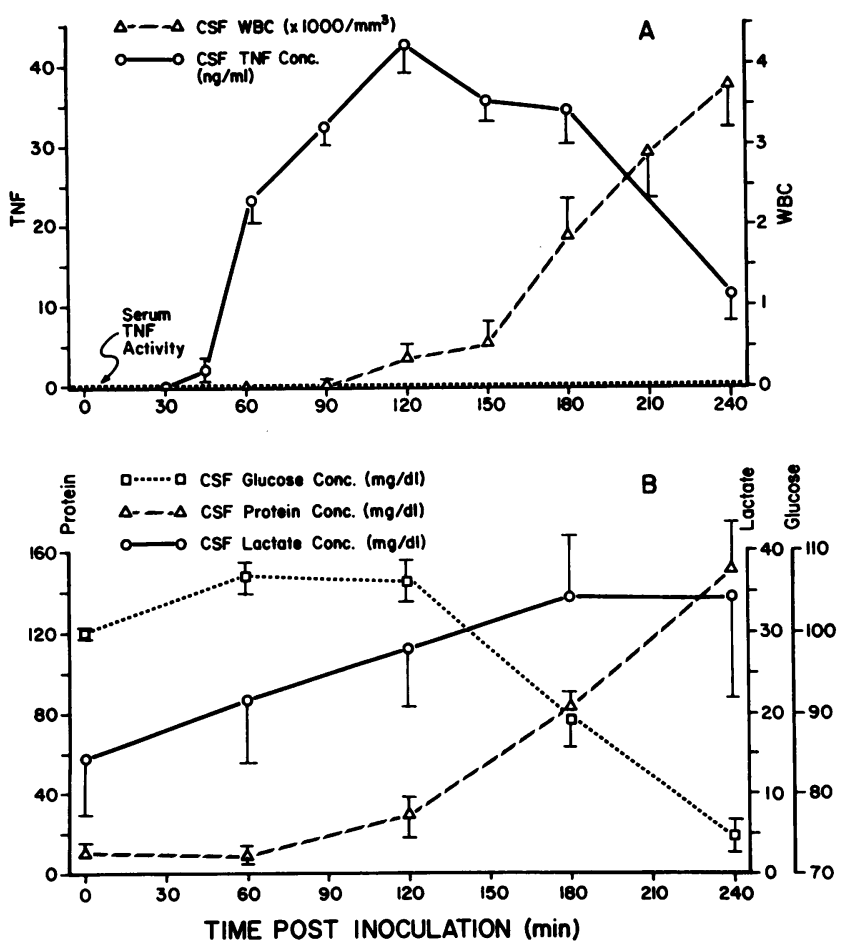

Figure 1. Induction of CSF TNF with $20 \mathrm{ng}$ Hib LOS intracisternally. Temporal relationships of CSF TNF concentrations with CSF WBC counts $(A)$ and with CSF protein, glucose, and lactate concentrations $(B)$ are shown. Note the absence of serum TNF activity. LOS was given at time 0 . (Four rabbits.) $\mathrm{ng} / \mathrm{ml}, P<0.05)$. Sera obtained simultaneously with CSF samples had no TNF activity.

CSF pleocytosis was first observed $2 \mathrm{~h}$ after Hib IC LOS administration intracisternally, and $75 \mathrm{~min}$ after TNF was first observed (Fig. $1 \mathrm{~A}$ ). The CSF WBC count continued to rise during the 4-h experimental period. The time course of other indices of meningeal inflammation in relation to TNF time course are shown in Fig. $1 B$. TNF concentrations peaked one hour before significant changes were observed in CSF WBC count, and in the protein and glucose concentrations. To determine whether there was any correlation between CSF TNF concentrations and the indices of meningeal inflammation, Pearson correlation coefficients were calculated for CSF TNF concentrations at 60,120 , and $180 \mathrm{~min}$ and for concentrations of the indices at 120,180 , and $240 \mathrm{~min}$ after induction of meningitis, respectively. There was no significant correlation present between CSF TNF activity and CSF concentrations of lactate, glucose, protein, and WBC count.

Intracisternal administration of 2, 20, and $200 \mathrm{ng}$ of purified Hib LOS resulted in peak CSF TNF concentrations at $2 \mathrm{~h}$ after induction of meningitis regardless of the dose used (Fig. 2). The overall effect of Hib LOS on CSF TNF concentrations for the three independent doses was significant $(P=0.02)$. However, there were no significant differences in mean peak CSF TNF concentrations when 2, 20, or $200 \mathrm{ng}$ of Hib LOS were used to induce meningitis. The overall effect of Hib LOS dose on CSF lactate and protein concentrations was also significant $(P<0.05)$.

When Hib organisms were administered intracisternally the peak TNF activity was observed at $3 \mathrm{~h}$ postinjection and TNF activity persisted for $14 \mathrm{~h}$ (Fig. 2). Comparing effects of $20 \mathrm{ng}$ of Hib LOS to $1-2 \times 10^{7}$ CFU of Hib on CSF TNF concentrations, there were no statistically significant differences in TNF concentrations at 120 and 180 min after induction of meningitis (i.e., the time of expected peak CSF TNF concentrations). By contrast, at 240 min postinduction, Hib LOS administration resulted in significantly lower CSF TNF concentrations compared with values after Hib organisms $(P<0.05)$.

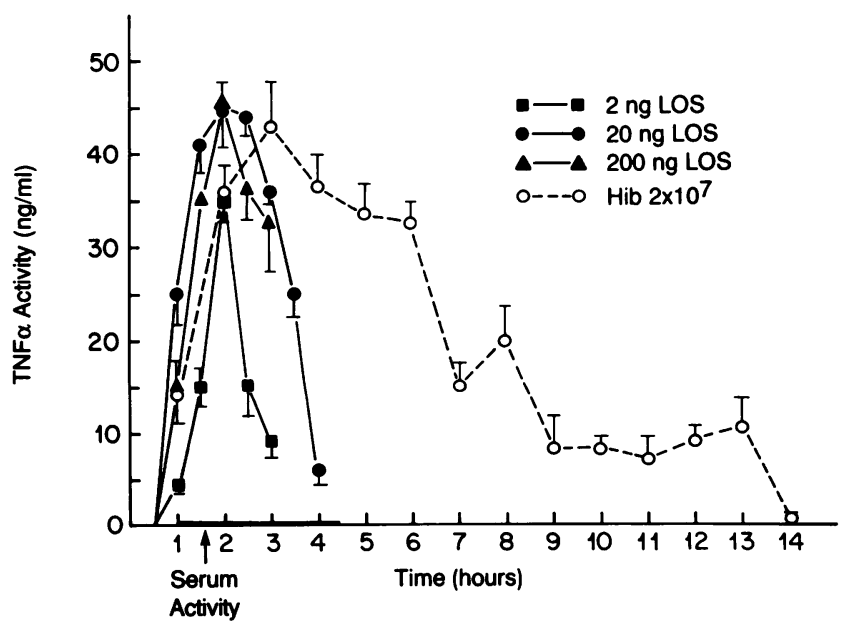

Figure 2. Induction of CSF TNF with intracisternal injection of Hib LOS or Hib organisms. LOS and Hib were administered at time 0 . (Four rabbits in each group.) 
Pyrogen-free saline injection produced an insignificant increase in CSF WBC counts and protein concentrations. TNF activity was not detected in the CSF of these rabbits.

Effects of dexamethasone treatment. Dexamethasone (1 $\mathrm{mg} / \mathrm{kg}$ ) was administered intravenously $1 \mathrm{~h}$ before, at the same time, and $30 \mathrm{~min}$ after intracisternal inoculation of $20 \mathrm{ng}$ of Hib LOS. Six rabbits did not receive dexamethasone and served as controls. Dexamethasone administered $1 \mathrm{~h}$ before or at the time of LOS inoculation resulted in significantly lower CSF TNF concentrations compared with those of animals that received dexamethasone $30 \mathrm{~min}$ after $L O S$ administration and of animals given LOS alone $(P=0.0001)$ (Fig. $3 A$ ).

In animals that received dexamethasone $1 \mathrm{~h}$ before or simultaneous with Hib LOS inoculation, significantly lower CSF protein and lactate concentrations and higher CSF glu-

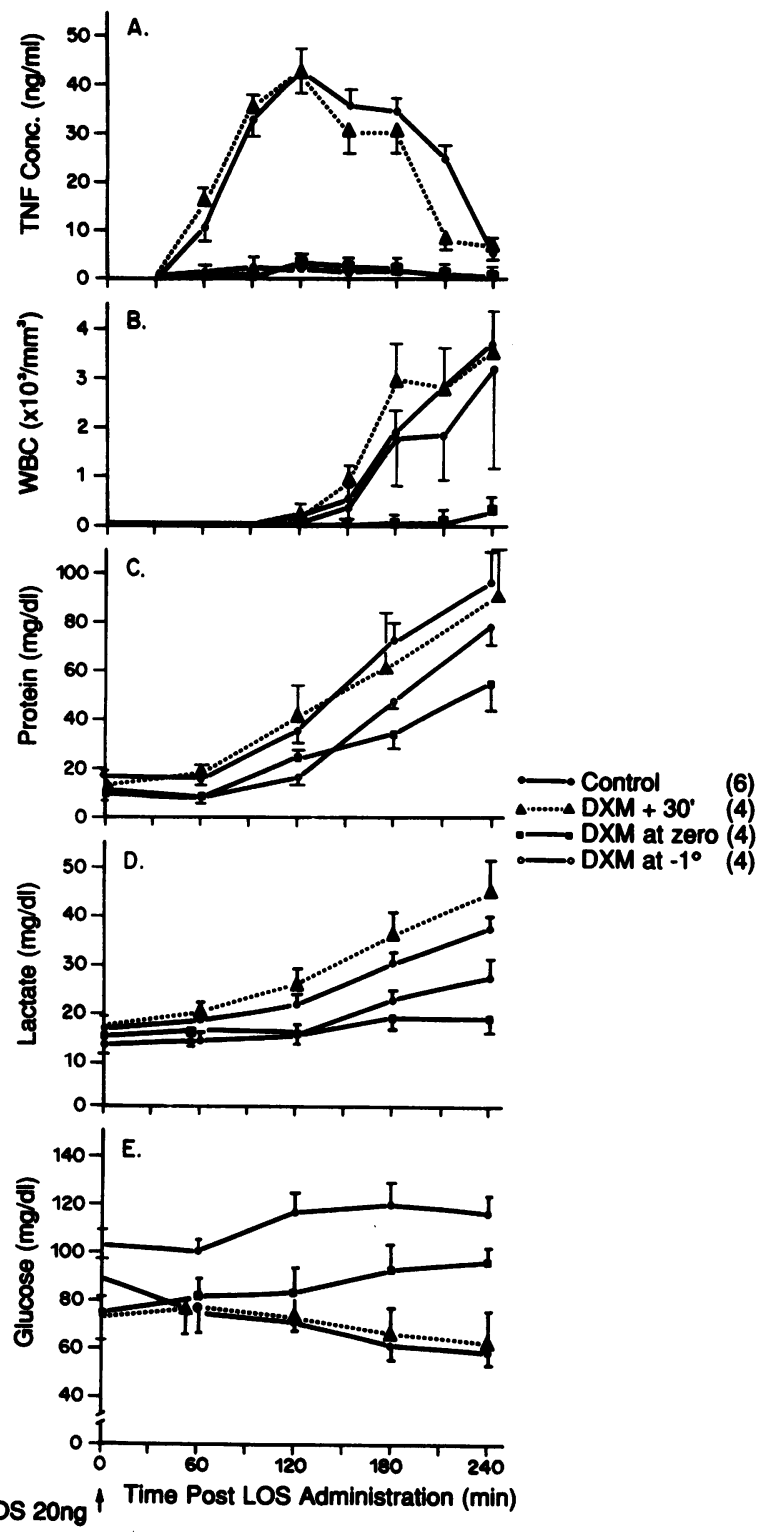

Figure 3. Changes in CSF TNF and indices of meningeal inflammation after intravenous dexamethasone treatment at three different times in relation to induction of meningitis by $20 \mathrm{ng}$ Hib LOS given IC at time 0. (Four rabbits in each group plus six controls.) cose concentrations $(P \leq 0.006)$ were observed compared with control animals and those that received dexamethasone $\mathbf{3 0}$ min after LOS. An overall effect of dexamethasone treatment on the CSF WBC count at three independent times in relation to induction of meningitis was borderline significant $(P$ $=0.09$ ). However, by comparing the WBC at each time with the corresponding values in control animals there was a significantly lower WBC count in CSF of rabbits treated with dexamethasone at the time of induction of meningitis compared with control rabbits $(P \leq 0.015)$ (Fig. $3 B$ ). By contrast, dexamethasone treatment $1 \mathrm{~h}$ before induction of meningitis significantly reduced the CSF lactate concentrations and increased CSF glucose concentrations $(P \leq 0.025)$ but had no significant effect on the CSF WBC count. There was no significant difference in CSF WBC in rabbits that received dexamethasone simultaneously or $1 \mathrm{~h}$ before LOS inoculation. Dexamethasone administered $30 \mathrm{~min}$ after LOS administration had no significant effects on CSF WBC count and glucose, protein, and lactate concentrations when compared with values obtained in control rabbits.

Effects of anti-TNF antibody administration. There was an overall significant effect of treatment with polyclonal antiTNF antibody on CSF TNF concentrations $(P=0.0001)$ after IC Hib LOS inoculation (Fig. 4). At the time of expected CSF TNF peak concentrations (i.e., 2 and $3 \mathrm{~h}$ postmeningitis induction) rabbits that received polyclonal anti-TNF antibody had significantly lower CSF TNF concentrations compared with those values obtained in control animals or in rabbits that received preimmune serum $(P<0.05)$. Moreover, anti-TNF antibody administration significantly reduced meningeal inflammation (Fig. 4). The lower CSF WBC count $(P=0.0085)$, lower lactate concentrations $(P=0.03)$ and higher glucose concentrations $(P=0.004)$ were significantly different from those in control animals and in rabbits given preimmune serum. When polyclonal anti-TNF antibody was administered intracisternally with and $1 \mathrm{~h}$ after inoculation of Hib organisms CSF TNF activity was significantly inhibited at 2,4 , and $8 \mathrm{~h}$ compared with that in CSF of the animals that received preimmune serum. The CSF WBC count was similar in both treatment groups at all times except $4 \mathrm{~h}$, at which time it was significantly smaller in those given anti-TNF antibody. Although CSF lactate and protein concentrations were smaller at all times in rabbits that received anti-TNF antibody, the differences were not significant except for protein concentrations at 4 and $8 \mathrm{~h}$ after inoculation of Hib.

\section{Discussion}

Bacterial meningitis in infants and children is associated with high morbidity and mortality rates (29). Although many advances have been made in treatment of bacterial meningitis, the outcome is unlikely to be improved with the advent of newer, more active antimicrobial agents. Better understanding of the pathophysiologic mechanisms of central nervous system injury during bacterial meningitis might provide new therapeutic directives.

In a model of experimental Haemophilus influenzae type b meningitis we have examined the role of TNF as a mediator of the inflammatory response in bacterial meningitis and studied whether treatment which inhibits TNF production or neutralizes its activities is associated with modulation of the meningeal inflammatory reactions. TNF was rapidly induced in vivo 

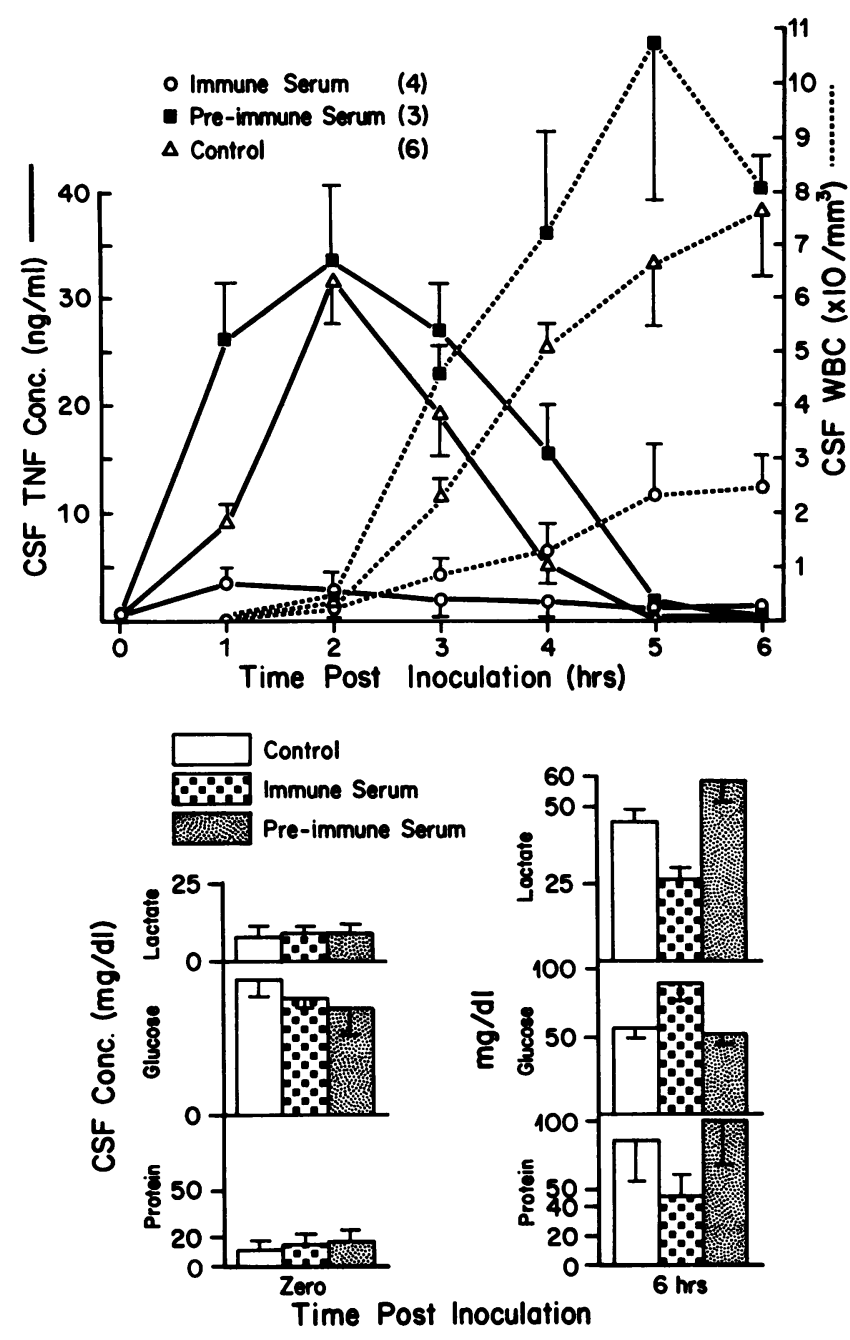

Figure 4. Comparative changes in CSF TNF and indices of meningeal inflammation after intracisternal administration of goat antiTNF antibody, preimmune goat serum, or control rabbits. (Four, three, and six rabbits, respectively.) Meningitis was induced with 20 ng Hib LOS administered intracisternally at time 0 .

after intracisternal injection of $\mathrm{Hib}$ or its purified endotoxin. Administration of dexamethasone intravenously or of antiTNF antibodies intracisternally with Hib LOS resulted in significantly decreased CSF meningeal inflammatory responses. Our studies provide, therefore, evidence for the possible role of $\mathrm{TNF}$ as a mediator of endotoxin-induced meningeal injury.

Elevated serum TNF concentrations have been shown to be a transient albeit crucial event in experimental endotoxemia and gram-negative septicemia $(11,12)$. In healthy volunteers, peak TNF serum concentrations were observed within 90 min after bolus intravenous endotoxin injection and TNF was no longer detectable after 3-4 h. Similar results were obtained from experimental animal endotoxemia studies which demonstrated, in addition, that TNF was maximally induced by as little as $10 \mu \mathrm{g}$ of LPS and that there were no significant differences in peak TNF serum levels when 250,50 , or $10 \mu \mathrm{g}$ LPS were used for TNF induction (13). Our data from the experimental model of endotoxin-induced meningitis demonstrated a similar temporal pattern of TNF production in CSF. TNF activity was detected in CSF as early as $45 \mathrm{~min}$, peaked at
$120 \mathrm{~min}$, and was no longer detected $5 \mathrm{~h}$ after intracisternal Hib LOS inoculation. Moreover, mean peak CSF TNF concentrations were not statistically significant when 2,20 , or 200 ng of Hib LOS were used to induce meningitis. Nevertheless, an overall significant effect of Hib LOS dose with time on CSF TNF concentrations was observed. The absence of TNF activity in sera obtained simultaneously with CSF from animals with meningitis indicates that the TNF detected in the CSF is principally produced within the central nervous system. It is likely that the cells responsible for TNF release in CSF are CNS macrophage-equivalent cells (astroglia and microglia) $(30,31)$.

The relative time of appearance for circulating TNF in baboons after infusion of a lethal dose of live $E$. coli were shown to be similar to that observed in endotoxin-challenged volunteers despite continuing bacteremia in the former group (12). The case in experimental $H$. influenzae type b meningitis compared with LOS-induced meningitis differed in two ways. CSF TNF concentrations peaked $3 \mathrm{~h}$ after Hib inoculation (compared with $2 \mathrm{~h}$ after LOS) and TNF activity persisted considerably longer in CSF of rabbits with Hib meningitis (4 vs. $14 \mathrm{~h}$ ). In another model of meningitis where Listeria organisms were injected intracerebrally into mice (17), TNF activity was first detected $3 \mathrm{~h}$ postinduction and continually increased during the ensuing 24-48 h. By comparison, we detected TNF activity in the CSF of $75 \%$ of infants and children with bacterial meningitis at the time of diagnosis and again, in much lower concentrations, $18-30 \mathrm{~h}$ later (16). On the other hand in vitro studies have indicated that continuous exposure of thioglycolate-stimulated peritoneal macrophages to LPS leads to transient rather than continuous TNF production (32). Accordingly, we hypothesize that recruitment of unstimulated monocytes and other inflammatory cells from peripheral circulation coupled with the continuous presence of endotoxin in the CSF from multiplying bacteria in experimental Hib meningitis might explain the prolonged presence of CSF TNF activity in this compartment.

In vitro studies have demonstrated that dexamethasone inhibits the production of TNF if administered to macrophages before endotoxin induction by both diminishing the quantity of TNF mRNA that is produced in response to endotoxin and by preventing its translation (33). Once induction has occurred, dexamethasone is incapable of regulating TNF biosynthesis. In our experimental meningitis model dexamethasone administered intravenously $1 \mathrm{~h}$ before or concomitant with Hib LOS reduced significantly TNF concentrations in CSF compared with those values obtained from control rabbits and from rabbits that received dexamethasone $30 \mathrm{~min}$ after intracisternal endotoxin challenge. Decreased production of TNF in CSF after dexamethasone treatment was associated with significant reduction in meningeal inflammation. The indices of meningeal inflammation were most favorably affected when dexamethasone was given with the LOS rather than $1 \mathrm{~h}$ before inoculation. As anticipated, dexamethasone given to infants and children with bacterial meningitis did not significantly affect TNF concentrations in CSF when measured 18 to $30 \mathrm{~h}$ after initiation of treatment (16). By contrast, we have demonstrated in experimental Hib meningitis that antibiotic treatment was associated with increased meningeal inflammation resulting from release of free endotoxin into CSF from dying organisms (34). This inflammatory reaction, mediated at least in part by TNF production in CSF, was 
reduced significantly when dexamethasone was given simultaneously with the antibiotic dose (34).

Intravenous administration of recombinant human TNF to animals produces the cardiovascular, inflammatory, metabolic, and histopathologic abnormalities observed in endotoxic shock and after endotoxin injection (9). Monoclonal antibodies to TNF or anti-TNF serum strongly attenuate these injurious effects and protect against TNF-induced fatality (5, 9). Recombinant human TNF produced a brisk inflammatory response after intracisternal inoculation in our animal model. The preparation, however, contained endotoxin which could not be satisfactorily removed by pretreatment with polymyxin B, as has been also shown by others (35). Simultaneous IC administration of goat anti-TNF serum with Hib LOS neutralized CSF TNF activity and was associated, in turn, with reduction of the meningeal inflammatory response as reflected by a significantly decreased mean CSF WBC count and lactate concentration and a significantly increased CSF glucose concentration. By comparison, CSF TNF activity was inhibited for $8 \mathrm{~h}$ after IC administration of polyclonal anti-TNF antibody and Hib organisms. Unlike the situation with LOS inoculation, the CSF WBC count and protein concentrations were only transiently reduced, which indicates the possible participation of other mediators of meningeal inflammation, such as IL-1.

In conclusion, we believe TNF participates in the meningeal inflammatory response after inoculation of $\mathrm{Hib}$ or $\mathrm{Hib}$ LOS in this animal model. It is likely, however, that other cytokines, such as IL-1, also play an important role in mediating meningeal inflammation induced by Haemophilus endotoxin. Quagliarello and associates (36) showed recently that recombinant human IL-1 inoculated intracisternally in rats produced CSF pleocytosis and alteration of the blood-brain barrier permeability, an effect that was significantly modulated by preincubation with IgG monoclonal IL-1 antibody. Additionally, IC inoculation of Hib LOS was shown to induce IL-1 in adult rats and IL-1 and TNF appeared to have a synergistic effect on blood-brain barrier permeability in this animal model system (37). Additional studies are required to clarify the role of these and possibly other cytokines in the pathogenesis of Haemophilus meningitis.

\section{Acknowledgments}

We would like to thank Patricia A. Thompson (Research Assistant II) in Bruce Beutler's lab for her help with the TNF bioassay.

\section{References}

1. Beutler, B., and A. Cerami. 1987. Cachectin: more than a tumor necrosis factor. N. Engl. J. Med. 316:379-385.

2. Dinarello, C. A. 1984. Interleukin-1. Rev. Infect. Dis. 6:51-95.

3. Ramila, P., and L. B. Epstein. 1986. Tumor necrosis factor as an immune modulator and mediator of monocyte cytotoxicity induced by itself, gamma-interferon and interleukin-1. Nature (Lond.). 323:86-89.

4. Okusawa, S., J. A. Gelfand, T. Ikejima, R. J. Connolly, and C. A. Diarello. 1988. Interleukin-1 induces a shock-like state in rabbits. Synergism with tumor necrosis factor and the effect of cyclooxygenase inhibition. J. Clin. Invest. 81:1162-1172.

5. Beutler, B., I. W. Milsark, and A. Cerami. 1985. Passive immunization against cachectin/tumor necrosis factor (TNF) protects mice from the lethal effect of endotoxin. Science (Wash. DC). 229:869-871.
6. Tracey, K. J., S. F. Lowry, T. J. Fahey III, J. D. Albert, Y. Fong, D. Hesse, B. Beutler, K. R. Manogur, S. Calvano, H. Wei, A. Cerami, and G. T. Shires. 1987. Cachectin/tumor necrosis factor induces lethal shock and stress hormone responses in the dog. Surg. Gynecol. Obstet. 164:415-419.

7. Tracey, K. J., S. F. Lowry, and A. Cerami. 1988. Cachectin: A hormone that triggers acute shock and chronic cachexia. J. Infect. Dis. $157: 413-420$.

8. Beutler, B., J. Mahoney, N. LeTrang, P. Pekala, and A. Cerami. 1985. Purification of cachectin, a lipoprotein lipase-suppressing hormone secreted by endotoxin-induced RAW 264.7 cells. J. Exp. Med. 161:984-995.

9. Tracey, K. J., B. Beutler, S. F. Lowry, J. Merryweather, S. Wolpe, I. W. Milsark, R. J. Hariri, T. J. Fahey III, A. Zentella, J. D. Albert, G. T. Shires, and A. Cerami. 1986. Shock and tissue injury induced by recombinant human cachectin. Science (Wash. DC). 234:470-474.

10. Tracey, K. J., Y. Fong, D. G. Hesse, K. R. Manogue, A. T. Lee, G. C. Kuo, S. F. Lowry, and A. Cerami. 1987. Anti-cachectin/TNF monoclonal antibodies prevent septic shock during lethal bacteremia Nature (Lond.). 330:662-664.

11. Michie, H. R., K. R. Manogue, D. R. Spriggs, A. Revhang, S. O'Dwyer, C. A. Dinarello, A. Cerami, S. M. Wolf, and D. W. Wilmore. 1988. Detection of circulating tumor necrosis factor after endotoxin administration. N. Engl. J. Med. 318:1481-1486.

12. Hesse, D. G., K. J. Tracey, Y. Fong, K. R. Manogue, M. A. Palladino Jr, A. Cerami, G. T. Shires, and S. F. Lowry. 1988. Cytokine appearance in human endotoxemia and primate bacteremia. Surg. Gynecol. Obstet. 166:147-153.

13. Mathison, J. C., E. Wolfson, and R. J. Ulevitch. 1988. Participation of tumor necrosis factor in the mediation of gram negative bacterial lipopolysaccharide-induced injury in rabbits. J. Clin. Invest. 81:1925-1937.

14. Waage, A., A. Halstensen, and T. Espevik. 1987. Association between tumor necrosis factor in serum and fatal outcome in patients with meningococcal disease. Lancet. i:355-357.

15. Girardin, E., G. E. Grau, J. M. Dayer, P. Roux-Lombard, The J5 Study Group, and P. H. Lambert. 1988. Tumor necrosis factor and interleukin-1 in the serum of children with severe infectious purpura. N. Engl. J. Med. 319:397-400.

16. Mustafa, M. M., M. H. Lebel, O. Ramilo, K. D. Olsen, J. S. Reisch, B. Beutler, and G. H. McCracken, Jr. 1989. Detection of interleukin- $1 \beta$ and cachectin in cerebrospinal fluid of infants and children with bacterial meningitis. J. Pediatr. 159:917-922.

17. Lest, T. P., K. Frei, S. Kam-Hansen, R. M. Zinkernagel, and A. Fontana. 1988. Tumor necrosis factor $\alpha$ in cerebrospinal fluid during bacterial, but not viral, meningitis. Evaluation in murine model infections and in patients. J. Exp. Med. 176:1743-1748.

18. Gulig, P. A., C. C. Patrick, L. Hermanstarfer, G. H. McCracken Jr., and E. J. Hansen. 1987. Conservation of epitopes in the oligosaccharide portion of Haemophilus influenzae type b. Infect. Immun. 55:513-520.

19. Westphal, O., and K. Jann. 1965. Bacterial lipopolysaccharides: extraction with phenol-water and further applications of the procedure. Methods Carbohydr Chem. 5:83-91.

20. Johnson, K. G., and M. B. Perry. 1976. Improved techniques for the preparation of bacterial lipopolysaccharides. Can. J. Microbiol. 22:29-34.

21. Tsai, M., and C. E. Frasch. 1982. A sensitive silver stain for detecting lipopolysaccharides in polyacrylamide gels. Anal. Biochem. 119:115-119.

22. Kimura, A., and E. J. Hansen. 1986. Antigenic and phenotypic variations of Haemophilus influenzae type b lipopolysaccharide and their relation to virulence. Infect. Immun. 51:69-79.

23. Syrogiannopoulos, G. A., E. J. Hansen, A. L. Erwin, R. S. Munford, J. Rutledge, J. S. Reisch, and G. H. McCracken Jr. 1988. Haemophilus influenzae type B lipooligosaccharide induces meningeal inflammation. J. Infect. Dis. 157:237-244. 
24. Mustafa, M. M., O. Ramilo, G. A. Syrogiannopoulos, K. D. Olsen, G. H. McCracken Jr., and E. J. Hansen. Induction of meningeal inflammation by outer membrane vesicles of Haemophilus influenzae type B. J. Infect. Dis. 159:917-922.

25. Wispelwey, B., A. L. Lesse, E. J. Hansen, and W. M. Scheld. 1988. Haemophilus influenzae lipopolisaccharide-induced blood brain barrier permeability during experimental meningitis in the rat. J. Clin. Invest. 82:1339-1346.

26. Flick, D. A., and G. E. Figgord. 1984. Comparison of in vivo cell cytotoxic assay for tumor necrosis factor. J. Immunol. Methods. 68:167-175.

27. Dacey, R. G., and M. A. Sande. 1974. Effects of probenecid on cerebrospinal fluid concentrations of penicillin and cephalosporin derivatives. Antimicrob. Agents Chemother. 6:437-441.

28. Miller, R. J. Jr. 1981. Simultaneous Statistical Inference. Springer-Verlag, New York. pp. 67.

29. Klein, J. O., R. D. Feigin, and G. H. McCracken, Jr. 1986. Report of the task force on diagnosis and management of meningitis. Pediatrics. 78:959-982.

30. Fontana, A., K. P. W. J. McAdam, F. Kristensen, and E. Weber. 1983. Biological and biochemical characterization of an interleukin-1 like factor from rat C-6 glioma cells. Eur. J. Immunol. 13:685-689.

31. Fontana, A., H. Hengartner, N. de Tribolet, and E. Weber.
1984. Glioblastoma cells release interleukin-1 and factors inhibiting interleukin-2 mediated effects. J. Immunol. 132:1937-1944.

32. Gifford, G. E., and M. L. Lohmann-Matthes. 1986. Requirement for the continued presence of lipopolysaccharide for production of tumor necrosis factor by thioglycollate-induced peritoneal murine macrophages. Int. J. Cancer. 38:135-137.

33. Beutler, B., N. Krochin, I. W. Milsark, C. Luedke, and A. Cerami. 1986. Control of cachectin (tumor necrosis factor) synthesis: Mechanisms of endotoxin resistance. Science (Wash. DC). 232:977980.

34. Mustafa, M. M., O. Ramilo, E. J. Hansen, B. Beutler, and G. H. McCracken, Jr. Modulation of inflammation and cachectin (TNF $\alpha$ ) activity in relation to treatment of experimental Haemophilus influenzae type b meningitis. J. Infect. Dis. In press.

35. Kluger, M. J., R. Singer, and S. M. Eiger. 1985. Polymyxin B use does not eusure endotoxin-free solution. J. Immunol. Methods. 83:201-207.

36. Quaglianello, V. J., W. J. Long, and W. M. Scheld. 1987. Human interleukin-1 modulases blood-brain barrier injury in vivo. Interscience Conference of Antimicrobial Agents and Chemotherapy. 614. (Abstr.)

37. Wispelwey, B., W. J. Long, J. M. Castracane, and W. M. Scheld. 1988. Cerebrospinal fluid interleukin-1 activity following intracisternal inoculation of Haemophilus influenzae type b lipooligosaccharide into rats. Interscience Conference of Antimicrobial Agents and Chemotherapy. 873. (Abstr.) 